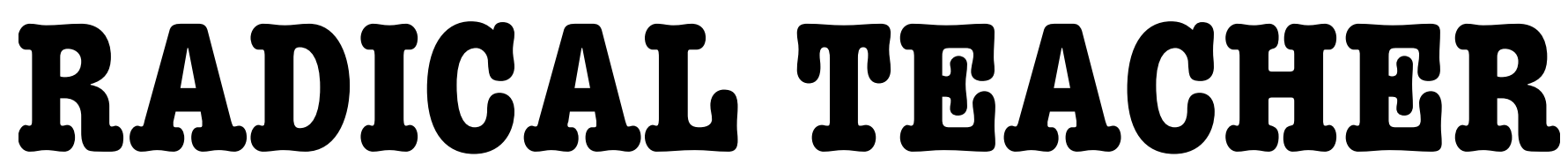

A SOCIALIST, FEMINIST, AND ANTI-RACIST JOURNAL ON THE THEORY AND PRACTICE OF TEACHING

\title{
A Night For Human Rights
}

\author{
by Julia Lourie
}

$\mathrm{H}$ uman Rights Watch recently launched its Young Professionals Network with an event, "A Night For Human Rights", to call attention to urgent human rights violations including America's mass incarceration epidemic and the current Syrian refugee crisis. The centerpiece of the evening was a contemporary art auction, co-curated by Marc Mayer, the Toronto-based Director of the National Gallery of Canada, and myself. The auction offered works by artists ranging from freshly emerging talents to successful late-career practitioners. I paid particular attention to young artists, and out of the $5 \mathrm{I}$ included, 4 of them were under age 25; the outlier was 86year-old Adelie Bischoff, a veteran painter of the Bay Area Figurative Movement.

I intentionally chose artists whose works had social, political, and existential dimensions to them in order to create a window through which people could enter a realm of compassion. Belenky's work "Study for Buttered Steel" features many dripping tea bags glued to the painting's surface, suggesting victimized bodies, mass loss of life, and dripping remainders of the things we've lost and those we miss. Briffa's photo-collage piece "Designed-In Danger (My Corvair)", spoke to the fragility of human life, and the physical risks we put ourselves in every day, whether by driving in cars on a highway or by using technology we know is under surveillance.

The artworks on display also helped open up topics related to human suffering, such as Nepalese artist Arpana Rayamajhi's handmade necklaces (from her "Wanderlust" and "I Wanna Go To Africa" series, respectively), which are constructed out of vibrant colors in protest of the patriarchal, subjugating tradition in Nepal that a women must only wear black once her husband dies. This, even, was a step back from their former tradition that a woman must self-immolate after her husband dies.

In many ways the event became a temporary forum for progressive social thought. However, it would be overly simple, though not incorrect, to say that "A Night For Human Rights" featured contemporary art because that type of art holds social cache. Was is it a carrot-and-stick maneuver to include art? Lure young, well-off individuals to an "art" event only to try and get them to care about social issues? Perhaps there was a bit of this, but smartly so. HRW leveraged contemporary art's cache to gain access to an audience that, with their money and influence combined, actually can make very measurable positive impacts on civil society.

\section{The artworks up for auction helped open people's hearts to what it means to be human, to create, to feel love, and to suffer like any other.}

In the end, the art did serve as an entry point for young folks to engage with the organization- but in a vastly more important sense, the art was included because the pieces speak about our present time. The artworks up for auction helped open people's hearts to what it means to be human, to create, to feel love, and to suffer like any other. It is my sincere hope that when the patrons who purchased artworks that night look at the pieces hanging on their walls that they are reminded of the power our actions have to affect others lives for the better, and the responsibility we all have to do so. 


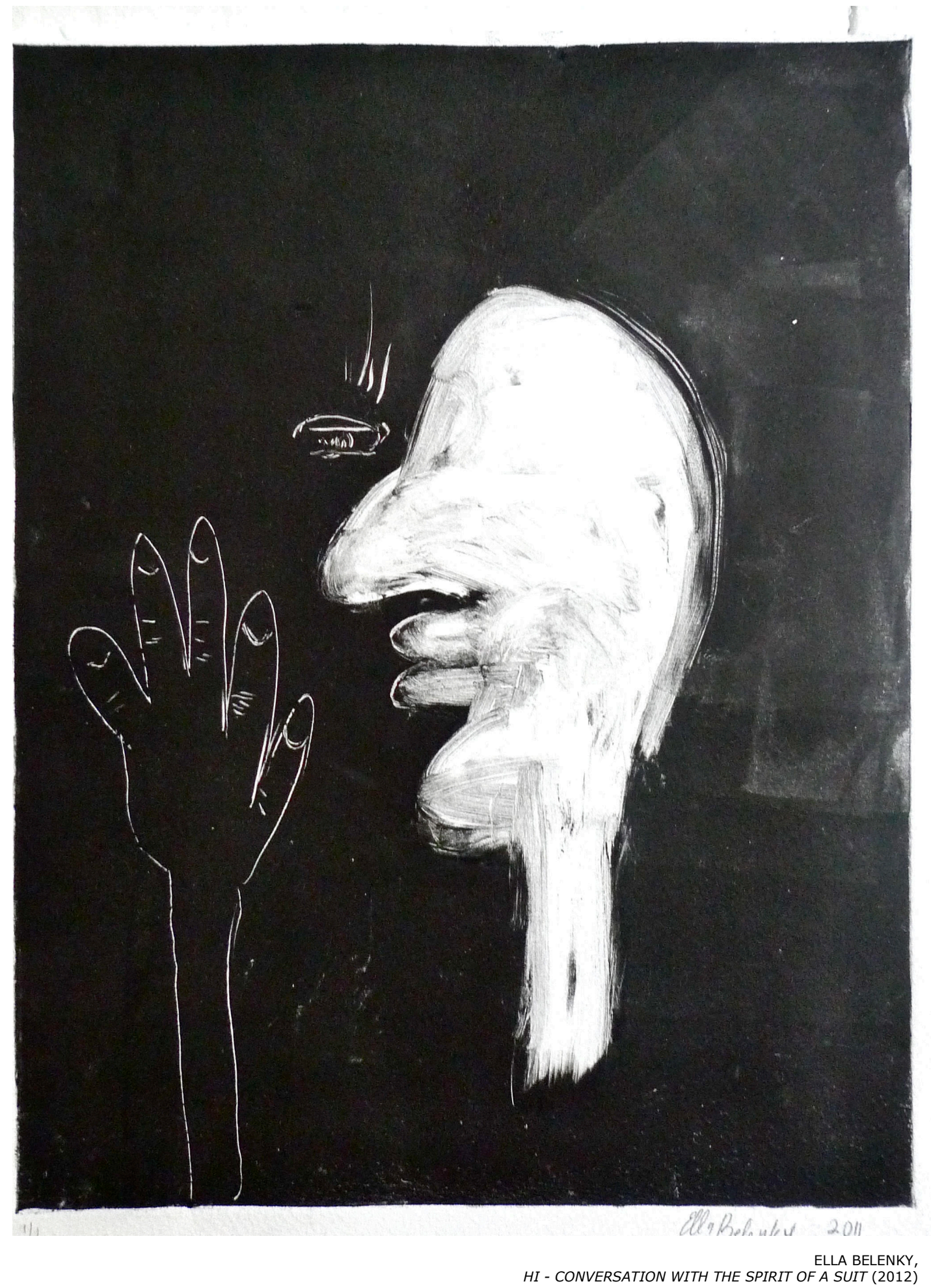




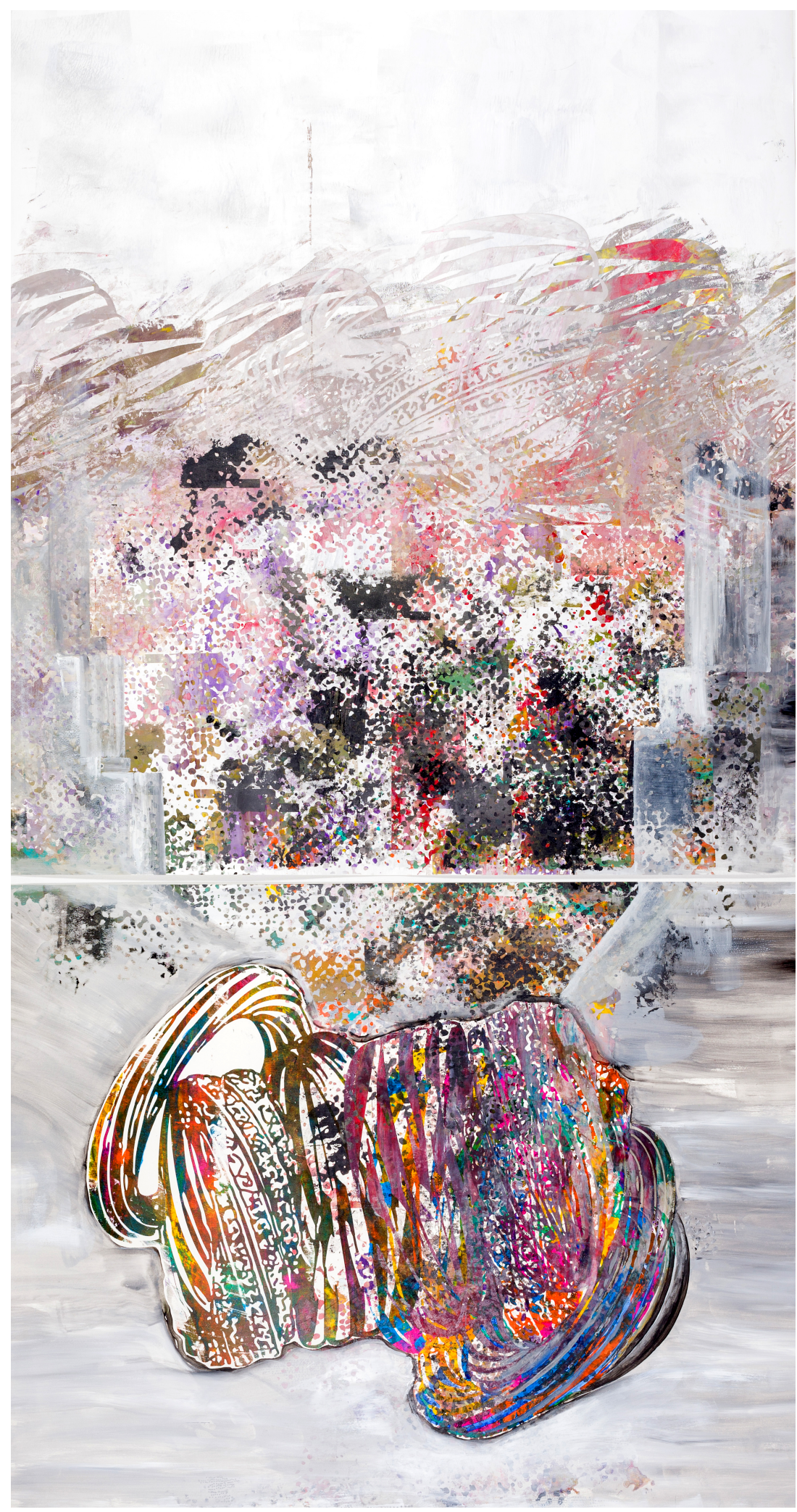

AMANDA HUGHEN AFGHAN 10 (010615A1A2 FROM ASSOCIATED PRESS), INK AND ACRYLIC PAINT ON PAPER, 72H X 37.75W IN., 2015

In the series Associated Press, Hughen mines the print edition of the New York Times to examine connections between geopolitics, class, identity, and luxury goods. For the past year, Hughen has worked primarily with imagery from a single edition: the January 6 , 2015 print edition of the New York Times. The headline photo that day was a large color portrait of an Afghani man who, since losing both sons in the conflict, spends his time ferrying dead bodies back to their families on both sides of the war. On the next page, A2, just behind his photo, was an ad for a Wempe gold ring that mimicked the form of the turban of the man on the cover. 

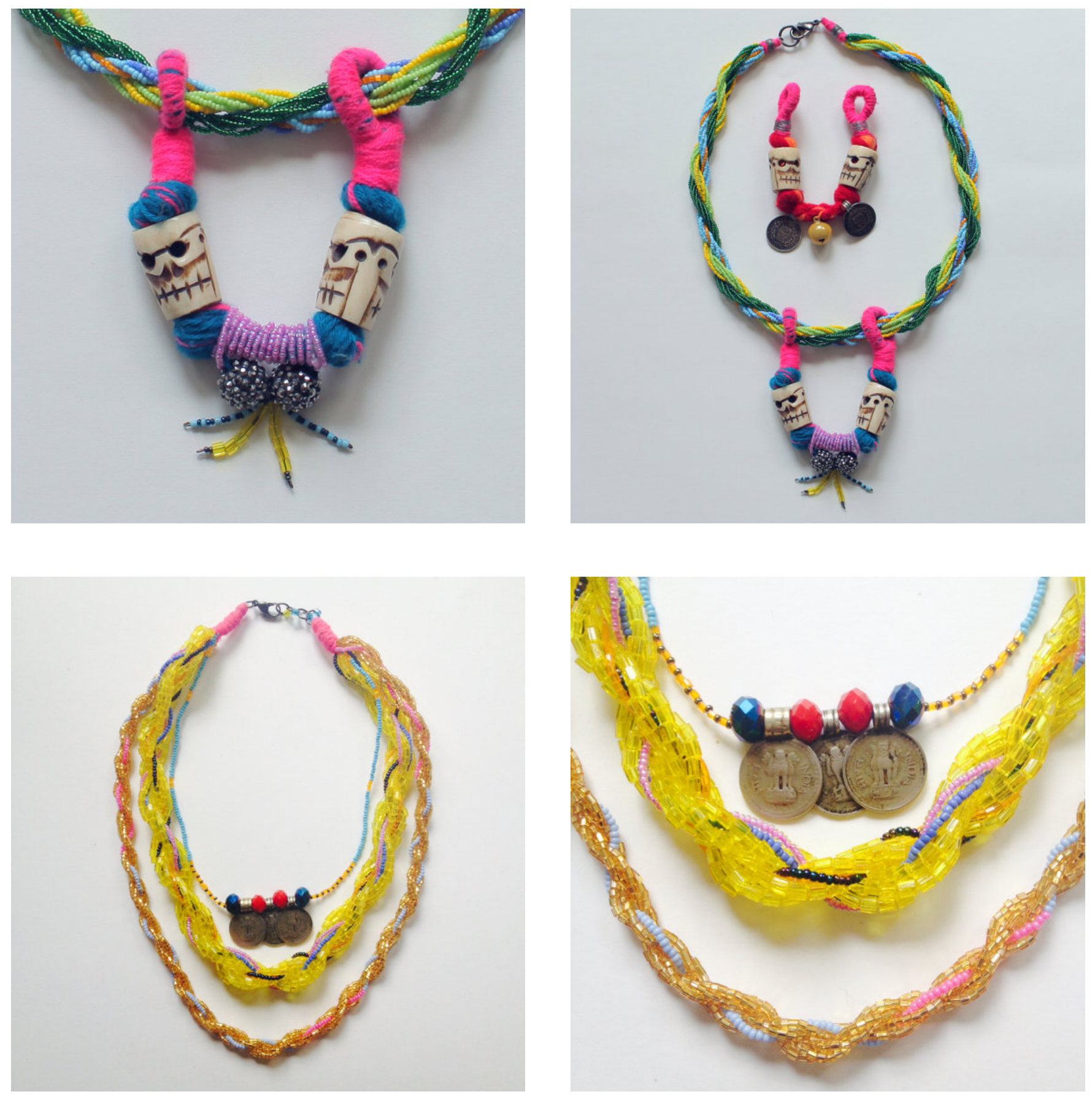

ARPANA RAYAMAJH "I WANNA GO TO AFRICA", AND WANDERLUST", BOTH 2015.

"Back home in Nepal color is a symbol of celebration, has deep religious significance, and is an integral part of everyday life. Growing up in a Hindu society where women are banned from wearing color upon the death of their husband, especially shades of red, is something that has affected me since I was a child. After losing my father, my mother's decision to wear red was criticized by many people, including women. I see the culture of stripping a woman from wearing color as a practice that is misogynistic and regressive. Color then seems to be a symbol of life, and in a way, not letting a woman wear color is telling her that her life, her identity, is completely linked to her husband's and therefore, she has no identity for herself. I am a woman, and I will use color whenever I want." 

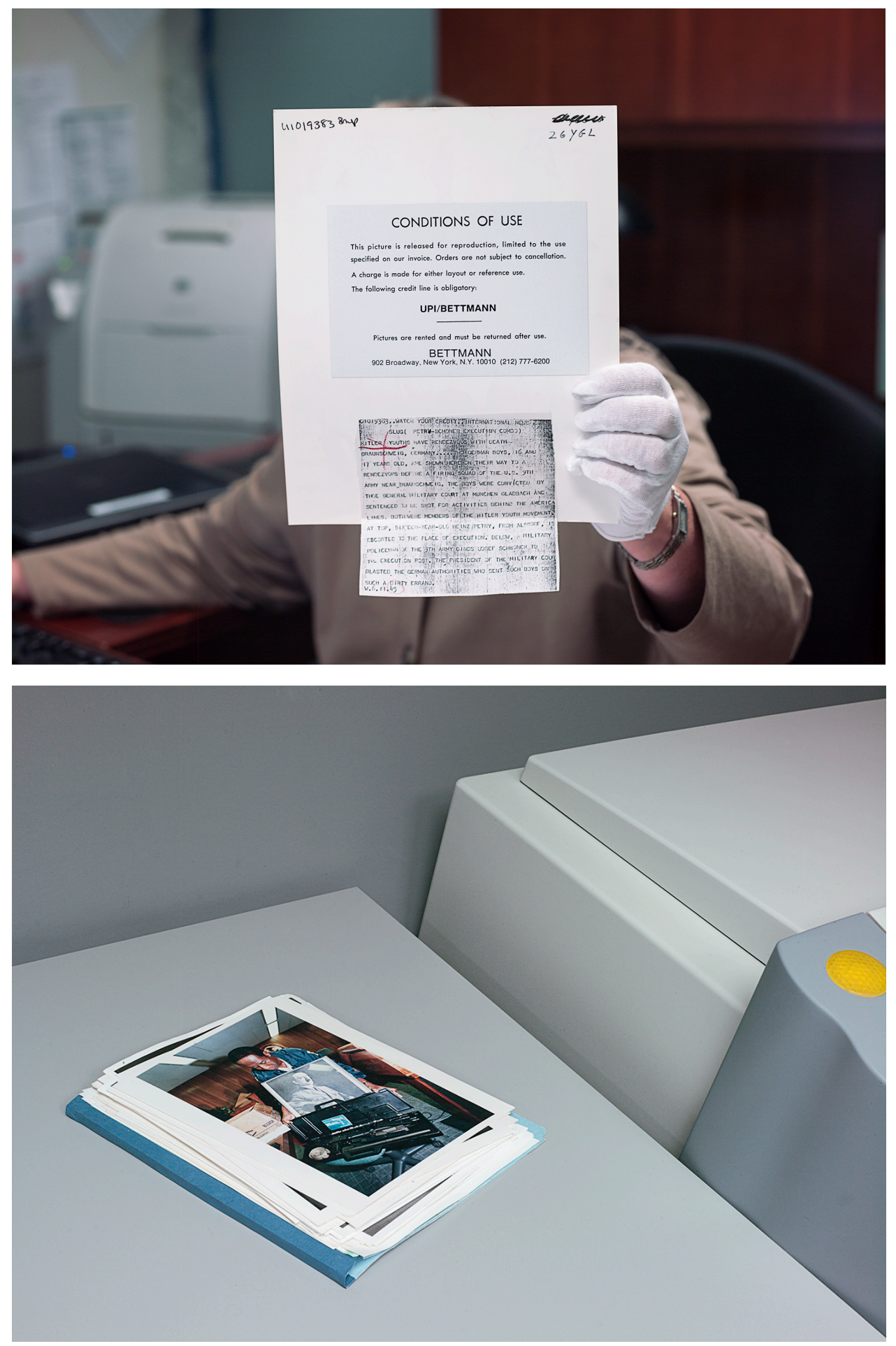

LUCAS BRIFFA, OPEN FOLDER (NAZIS) AND PETRY/SCHONER EXECUTION COMBO, BOTH 2014, ARCHIVAL INKJET PRINT, 32" X 24"

"Hitler Youths have rendezvous with death. Braunschweig, Germany....Two German boys, 16 and 17 years old, are shown here on their way to a rendezvous before a firing squad of the U.S. 9th army near Braunschweig. The boys were convicted by the general military court at Munchen Gladbach and sentenced to be shot for activities behind the American lines. Both were members of the Hitler Youth Movement. At top, 16-year-old Heinz/Petry, from Alsdorf is escorted to the place of execution. Below, a military policeman of the 9th army binds Josef Schoner to the execution post. The president of the military court blasted the German Authorities who sent such boys on such a dirty errand."

\section{$(\mathrm{ccc})$ EY-NC-ND}

UILIS D-Sork

\section{This work is licensed under a Creative Commons Attribution-Noncommercial-No Derivative Works 3.0 United States License.}

This journal is published by the University Library System of the University of Pittsburgh as part of its D-Scribe Digital Publishing Program, and is cosponsored by the University of Pittsburgh Press.

\section{RADICAL TEACHER}

http://radicalteacher.library.pitt.edu 